\title{
POSSIBLE CAUSES OF DEATH OF A NESTLING GREAT GRAY OWL
}

SPENCER G. SEALY ${ }^{1}$ and ROBERT W. NERO ${ }^{2}$

${ }^{1}$ Department of Biological Sciences, University of Manitoba, Winnipeg, MB R3T 2N2

${ }^{2} 546$ Coventry Road, Winnipeg, MB R3R $1 B 6$

\section{Introduction}

Nestling deaths are not unusual in many species of birds that rely on prey whose availability may decline when the demand is greatest, during the chick-rearing period. ${ }^{1}$ Brood reduction has been recorded in hawks and owls in cases of food shortage where adults occasionally kill their young (infanticide), or kill and eat them (cannibalism), or, in other cases, young may starve and are eaten by an adult or surviving siblings (scavenging). ${ }^{2}$ Depredation by a variety of potential predators is always a possibility as well but before the use of surveillance cameras focused on active nests observers were usually only able to determine that a nestling died, not why it died or how it was killed. In this article, we present a case study of a nestling Great Gray Owl that died and evaluate the possible causes of death.

\section{Case Study}

During some winters, Great Gray Owls (Strix nebulosa) move widely in search of voles whose densities fluctuate over the landscape- some individuals die, whereas others settle in areas with ample prey and breed..$^{3-6}$ In late 1973 and through the winter of 1974 , we recorded an increase in the number of Great Gray Owls observed in southeastern Manitoba, including the area around Lac du Bonnet. In early April 1974, we flushed a female from an empty nest in a stand of eastern cottonwood (Populus deltoides) along a road southeast of Lac du Bonnet $\left(50^{\circ} 15^{\prime} \mathrm{N}, 96^{\circ} 4^{\prime} \mathrm{W}\right)$. The female was sitting on a different nest nearby when we next visited the site, in mid-April, but by 1 May, a clutch of three eggs had been laid in the nest from which we originally flushed the female. On 1 June, by climbing a neighbouring tree, small young could be seen in the nest (Figures 1,2), but by 13 June one of the chicks had disappeared, leaving two young. On 21 June, we found the wing of a gray owl nestling on the ground under the nest, neatly severed from the body (Figure 3 ). The wing, catalogued in the collection of the University of Manitoba Zoology Museum (UMZM 2933), 


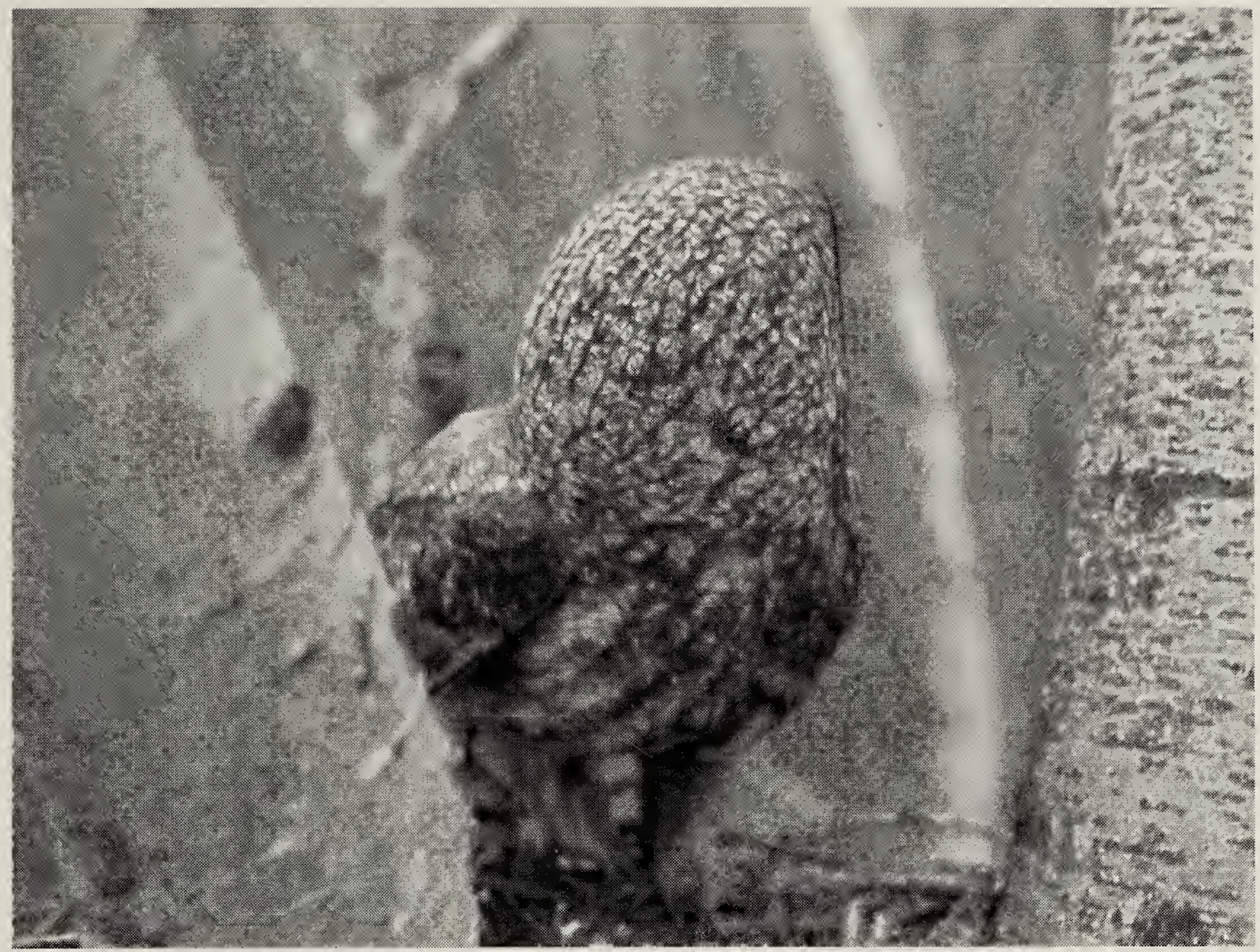

Figure 1. Great Gray Owl, standing over three recently hatched young, distracted momentarily by the male's calls a short distance from the nest, near Lac du Bonnet, Manitoba, 1 June 1974.

-S.G. Sealy

bore recently unsheathed therefore, when distinguishing primaries and secondaries (Figure between acts of infanticide, 3 ). The cause of this nestling's scavenging and cannibalism, death was not determined but the heeding McNicholl's caution that remains provide an opportunity to speculate on a possible cause of its death.

The conclusion of death of nestlings often is based only on the premature disappearance of one or more young from the nest, ${ }^{7}$ because the event is seldom witnessed, ${ }^{8-10}$ although use of video cameras may change this. ${ }^{10}$ Careful observations are needed, "The selection pressures for eating an already dead animal may be substantially different from those involved in killing another animal of the same species, especially kin, and then eating it". ${ }^{2}$ Here, we examine each of these behaviours, as well as predation, in seeking an explanation for the death of this nestling Great Gray Owl. 


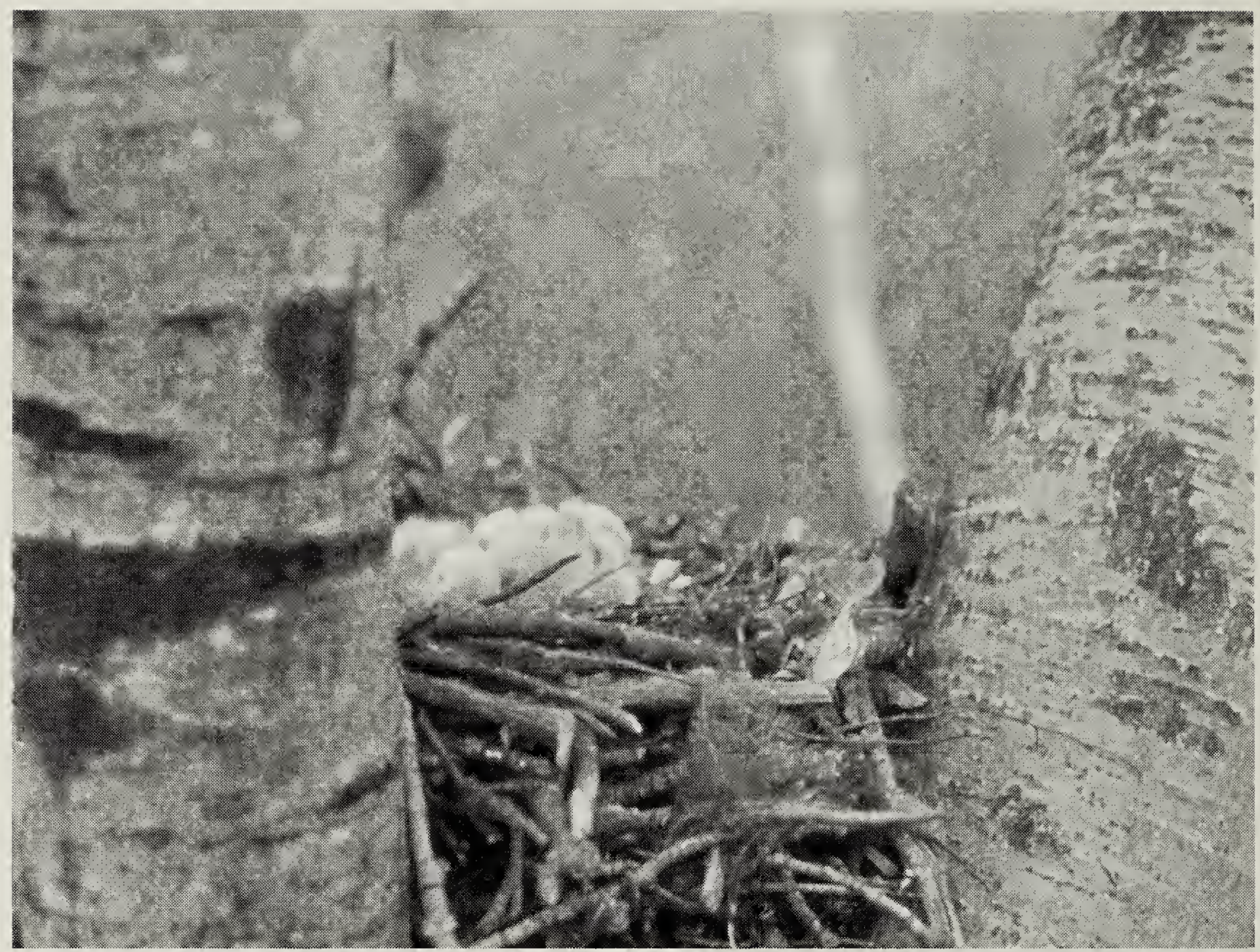

Figure 2. Three recently hatched young Great Gray Ow/s, near Lac du Bonnet, Manitoba, 1 June 1974.

-S.G. Sealy

Infanticide and cannibalism involve individuals of the same species. ${ }^{2,12,13}$ Cannibals are genetically related or unrelated individuals that feed on alreadydead individuals of the same species, whereas infanticide is a behaviour in which an adult aggressively kills offspring (termed filial infanticide if the young are its own), which may be followed by the parents' consumption of the young (filial cannibalism). ${ }^{7,8,10,11}$ Killing of dependent offspring or eating already-dead individuals, such as those that have starved, may provide direct or indirect fitness benefits to the perpetrator; in the first case, males may gain access to females or increase available resources and the chances of survival of at least some of the young ${ }^{11}$ or, in the latter case, supplement the food supply. ${ }^{10}$ Depredation involves individuals killing and eating unrelated individuals.

We believe that none of these brood-reduction scenarios occurred at this nest, because we would have expected the salvaged portion of the wing to have been among other remains egested in pellets, with the bones partially digested and 
disarticulated, and the feathers initially wet but now in disarray. This was not the case, as the wing and its feathers were intact and not disheveled (Figure 3), suggesting the nestling had died and was in some way removed from the nest, or it accidently fell out of the nest, perhaps when the female owl flushed. ${ }^{5}$ On the ground, the carcass may have been scavenged by a mammal, as the wing appeared to have been severed cleanly from the body (Figure 3 ). Another possibility is that the nestling was killed in the nest and removed by an avian or mammalian predator, ${ }^{6}$ but this leaves us in the uncomfortable position of guessing its identity based on a list of possible predators that are known to occur in the area, especially because there were no clues such as identifiable tracks or tell-tale feathers in the vicinity.

We cannot know what befell this nestling other than that it died, or it was killed, and apparently partially consumed. Was it the lasthatched young in the brood and, therefore, several days younger and possibly less competitive than its older siblings? Disparities in the ages of individuals in broods

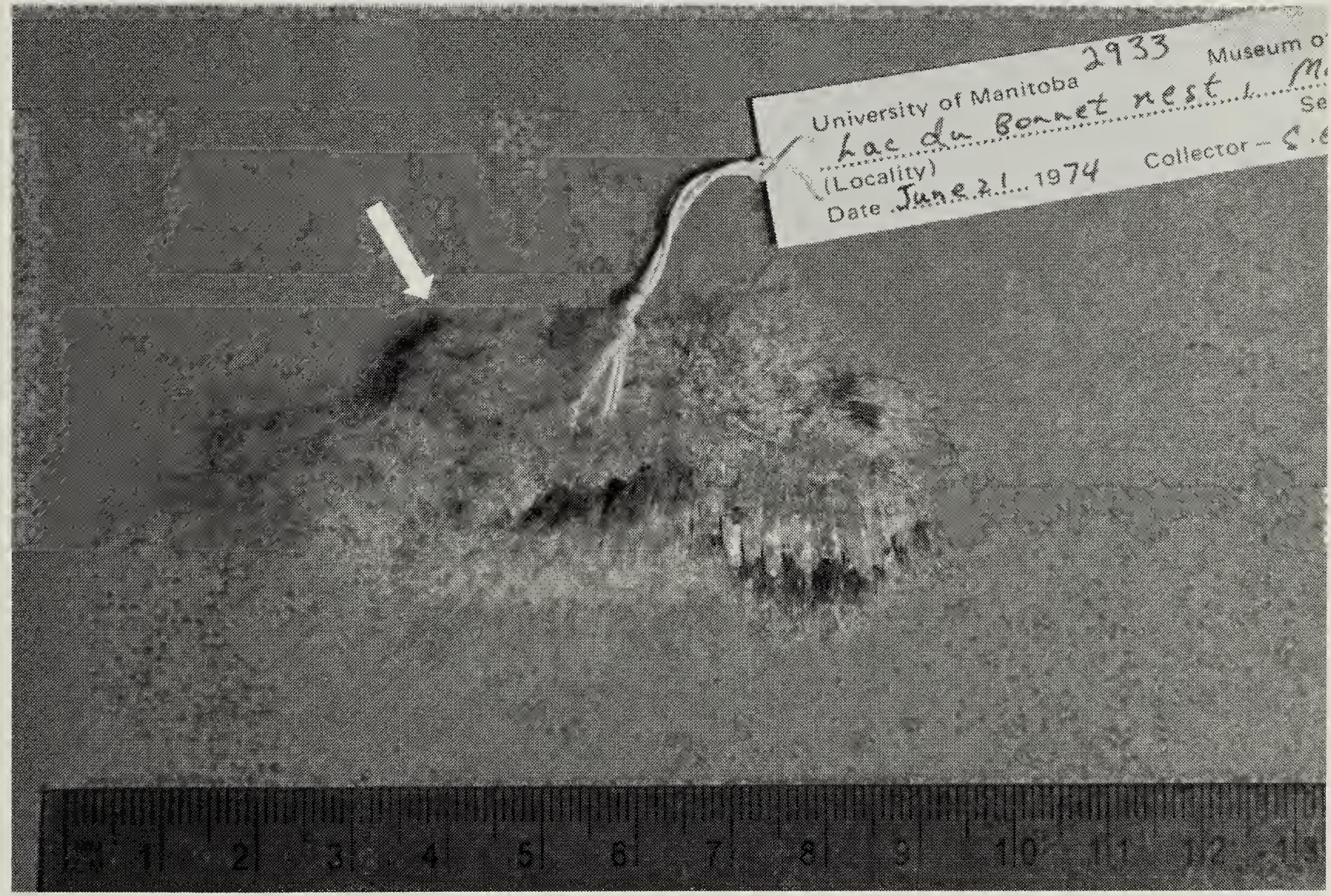

Figure 3. Ventral side of left wing of nestling Great Gray OWI (UMZM 2933) found under a nest near Lac du Bonnet, Manitoba, 21 June 1974. Arrow points to the humerus where the wing was severed. The recently unsheathed primaries and secondaries are visible. 
of species such as the Great Gray Owl, which initiate incubation as soon as the first egg is laid, set up the means to feed the larger and older young in cases of food shortages. Further research, using video cameras, may establish the prevalence of the different sources of mortality during brood reduction in raptorial species, and their various ecological effects.

\section{Postscript}

The two siblings, both banded, left the nest (Figure 4) but it was not determined whether they survived to independence. We inspected the nest late the following winter in anticipation of it being used again in 1975, but undisturbed snow in the nest bowl in March (Figure 5) suggested that a Great Gray Owl was not visiting it. Subsequent visits that year and for at least the following three years confirmed that these nests were not used again

\section{Acknowledgements}

We appreciate the companionship of Herbert W. R. Copland and the late Robert $R$. Taylor during many of our forays throughout southeastern Manitoba and northwestern Minnesota in search of Great Gray Owls and their nests. James C. Duncan commented on an early draft of the manuscript, and we thank Blue Jay editors and an anonymous reviewer for editorial comments on a later draft.

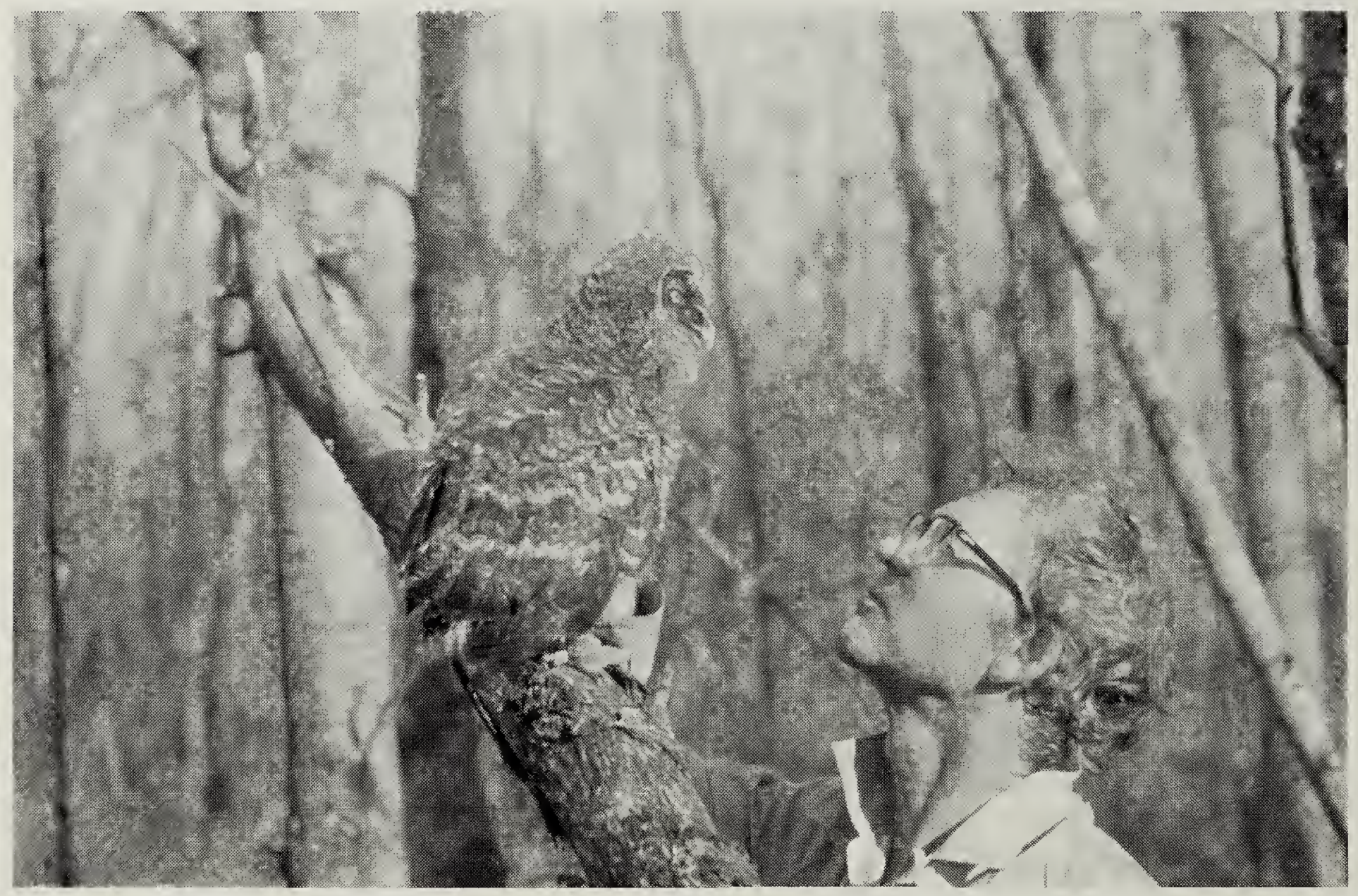

Figure 4. Robert W. Nero and one of two Great Gray Owls that fledged from a nest near Lac du Bonnet, Manitoba, July 1974. $\quad$-S. G. Sealy 


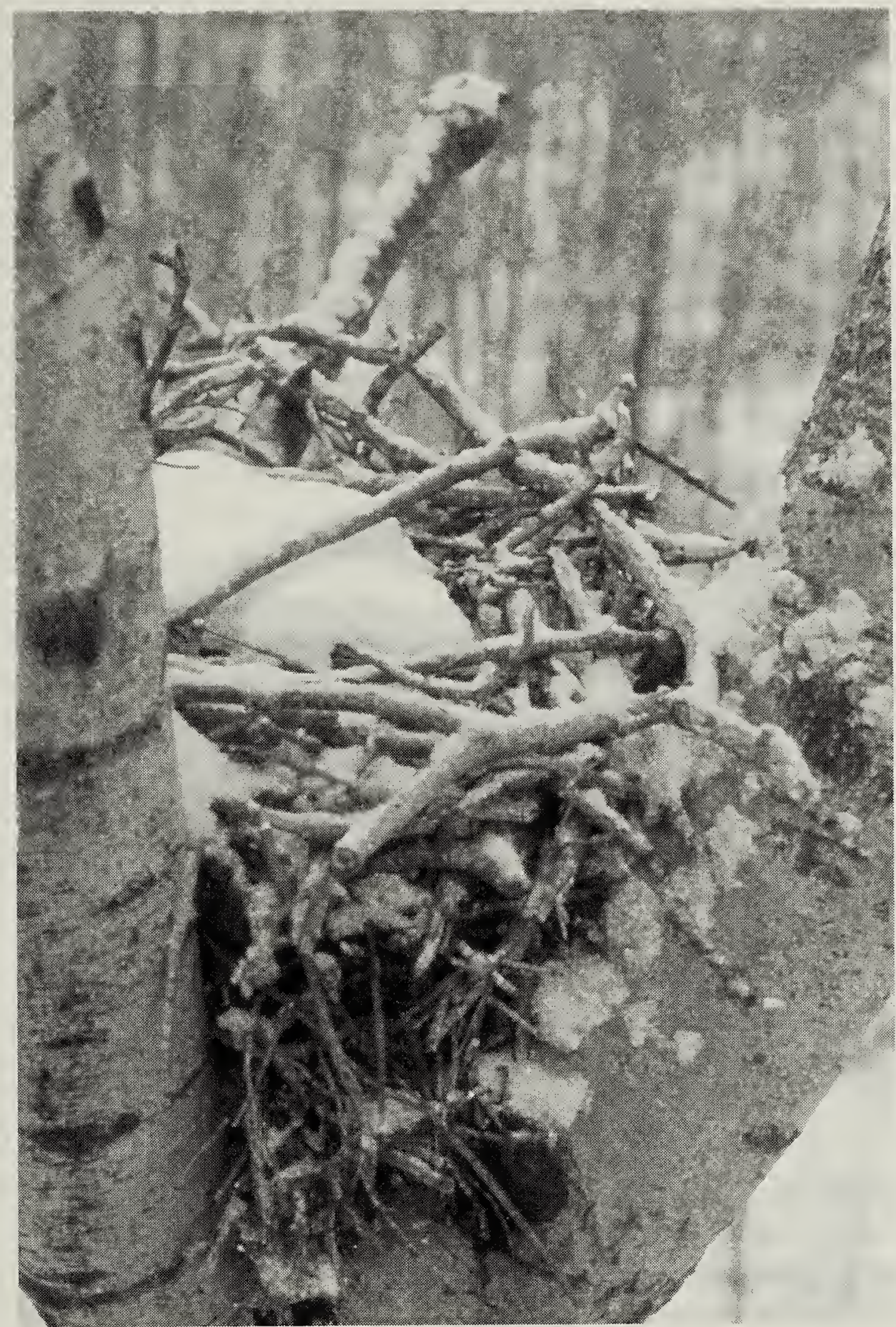

Figure 5. Nest near Lac du Bonnet, Manitoba, from which two Great Gray Owls fledged in 1974. Undisturbed snow in the nest bowl in late March 1975 suggested that this nest would not be used again that year, which was later confirmed.

-S. G. Sealy

1. Stoleson $\mathrm{SH}$, Beissenger SR (1995) Hatching asynchrony and the onset of incubation in birds, revisited. Current Ornithology 12:191-270.
2. McNicholl MK (1977) Usage of the terms "cannibalism" and "scavenging" in ecological literature. Canadian FieldNaturalist 91:416. 
3. Nero RW (1969) The status of the Great Gray Owl in Manitoba, with special reference to the 1968-69 influx. Blue Jay 27:191-209.

4. Collins KM (1980) Aspects of the biology of the Great Gray Owl, Strix nebulosa nebulosa Forster. M.Sc. thesis, University of Manitoba, Winnipeg.

5. Nero RW (1980) The Great Gray Owl: Phantom of the northern forest. Smithsonian Institution Press, Washington, D.C.

6. Bull EL, Duncan JR (1993) Great Gray Owl (Strix nebulosa), no. 41 in The Birds of North America (Poole A, Gill F, editors). Philadelphia: The Academy of Natural Sciences; Washington, D.C.: The American Ornithologists' Union.

7. Ingram C (1959) The importance of juvenile cannibalism in the breeding biology of certain birds of prey. Auk 76:218-226.

8. Mock DW (1984) Infanticide, siblicide, and avian nestling mortality. In: Infanticide: comparative and evolutionary perspectives, Hausfater G, Hrdy SB, editors. Aldine Press, New York. p. 3-30.

9. Bortolotti GR, Wiebe $\mathrm{KL}$, Iko WM (1991) Cannibalism of nestling American Kestrels by their parents and siblings. Canadian Journal of Zoology 69:1447-1453.

10. Solaro C, Sarasola JH (2012)

First observation of infanticide and cannibalism in nest of Chimango Caracara (Milvago chimango). Journal of Raptor Research 46:412413.

11. Hubbard JK, Tobin AL (2012) Malicious motherhood: Instance of infanticide by a female Barn Swallow. Wilson Journal of Ornithology 124:608-611.

12. Allen ML, Taylor AP (2013) First record of scavenging by a Western Screech-Owl (Megascops kennicottii). Wilson Journal of Ornithology 125: 417-419. 